PHYSICAL REVIEW B 67, 149901(E) (2003)

\title{
Publisher's Note: Phase diagram of a spin ladder with cyclic four-spin exchange [Phys. Rev. B 67, 100409 (2003)]
}

A. Läuchli, G. Schmid, and M. Troyer

(Received 8 April 2003; published 15 April 2003)

DOI: 10.1103/PhysRevB.67.149901

PACS number(s): 75.10.Jm, 75.40.Mg, 75.40.Cx, 99.10.Fg

This paper was published online on 31 March 2003 with a missing line at the bottom of the second column of the first page. It has been corrected as of 10 April 2003. The text is correct in the printed version of the journal. 